\title{
STOP-Bang and NoSAS questionnaires as a screening tool for OSA: which one is the best choice?
}

\author{
(iD) José Coutinho Costa \\ (iD) Alexandre Rebelo-Marques $2,3,4$ \\ (iD) João Pedro Neiva Machado ${ }^{1}$ \\ Bruno Miguel Figueiredo Valentim ${ }^{5}$ \\ Cláudia Sofia de Almeida Vicente Ferreira ${ }^{6}$ \\ (iD) Joana Daniela Oliveira Gonçalves ${ }^{7}$ \\ (iD) Jorge Manuel dos Reis Gama \\ (iD) Maria de Fátima Lopes Teixeira ${ }^{1,9}$ \\ (iD) Joaquim Jorge Marques Moita ${ }^{1,9}$
}

\begin{abstract}
1. Pneumology Service, Hospital and University Center of Coimbra, Coimbra, Portugal
2. Faculty of Medicine, University of Coimbra, Coimbra, Portugal

3. Clinical Academic Center of Coimbra, Portugal

4. Institute of Clinical and Biomedical Investigation of Coimbra (iCBR), Faculty of Medicine, University of Coimbra, Portugal

5. USF Condeixa, ACeS Baixo Mondego, ARS Center, Coimbra, Portugal

6. UCSP Mealhada, ACeS Baixo Mondego, ARS Center, Coimbra, Portugal

7. UCSP Celas, ACeS Baixo Mondego, ARS Center, Coimbra, Portugal

8. Department of Mathematics, University of Beira Interior, Covilhã, Portugal

9. Sleep Medicine Center, Hospital and University Center of Coimbra, Coimbra, Portugal
\end{abstract}

http://dx.doi.org/10.1590/1806-9282.66.9.1203

\section{SUMMARY}

INTRODUCTION: Currently there has been significant growth in the number of patients with suspected obstructive sleep apnea (OSA) referred to sleep clinics. In this sense, screening and stratification methods of the severity of this pathology have become increasingly relevant.

OBJECTIVE: To evaluate the performance of the NOSAS and STOP-Bang scores in the screening of OSA in a sleep clinic.

METHODS: Prospectively, for 12 months, all patients referred by primary care physicians to our sleep unit for clinical evaluation and who underwent in-lab polysomnography (PSG), also completed the NoSAS score (Neck circumference, Obesity, Snoring, Age, Sex) and STOP-Bang (Snoring, Tiredness, Observed apnea, Pressure (high blood), BMI, Age, Neck circumference, Gender). A ROC (receiver operating characteristic) analysis was used to find the scores that simultaneously maximize sensitivity and specificity for each diagnosis. RESULTS: Of the 294 individuals included, 84\% had OSA, of which 28.8\% were mild, 34.8\% moderate, and 36.4\% were severe.

USING THE NOSAS SCORE FOR PREDICTING OSA, MODERATE TO SEVERE OSA, AND SEVERE OSA, THE ROC AREA WAS: 0.770 (95\% Cl: 0.7030.837), $p<0.001$, sensitivity of $57.5 \%$, and specificity of $83.0 \%$ for a score of 12; 0.746 (95\% Cl: 0.691-0.802), $p<0.001$, sensitivity of $68.2 \%$ and specificity of $75.4 \%$ for a score of 13; 0.686 (95\% Cl: 0.622-0.749), $p<0.001$, sensitivity of $71.1 \%$ and specificity of $58.3 \%$ for a score of 13 , respectively.

USING THE STOP-BANG SCORE FOR PREDICTING OSA, MODERATE TO SEVERE OSA, AND SEVERE OSA, THE ROC AREA WAS: 0.862 (95\% Cl: 0.808-0.916), $p<0.001$, sensitivity of $68.4 \%$ and specificity of $85.1 \%$ for a score of 5; 0.813 (95\% Cl: 0.756-0.861), $p<0.001$, sensitivity of $77.3 \%$ and specificity of $66.1 \%$ for a score of 5; 0.787 (95\% Cl: 0.732-0.841), $p<0.001$, sensitivity of $70.0 \%$ and specificity of $79.9 \%$ for a score of 6 , respectively.

CONCLUSIONS: The ROC area was consistently high for both scores confirming the diagnostic ability of the NoSAS and STOP-Bang questionnaires for all OSA severities. Thus, our results suggest that these questionnaires may be a powerful tool for the screening and stratification of patients in the diagnosis of OSA. Overall, the diagnostic ability of the STOP-Bang was higher than the NoSAS.

KEYWORDS: Sleep apnea, obstructive. Surveys and questionnaires. Health surveys.

DATE OF SUBMISSION: 23-Jan-2020

DATE OF ACCEPTANCE: 22-Mar-2020

CORRESPONDING AUTHOR: José Coutinho Costa

Quinta dos Vales - São Martinho do Bispo - 3041-801 Coimbra, Coimbra, Portugal - 3041-801

E-mail: josecoutinhocosta99@gmail.com 


\section{INTRODUCTION}

Obstructive sleep apnea syndrome (OSA) is characterized by obstruction of the upper respiratory tract leading to increased respiratory effort with inadequate ventilation. These episodes are essentially accompanied by desaturation, increased activity of the sympathetic nervous system with frequent arousals. It can lead to chronic intermittent hypoxia, hypercapnia, and sleep fragmentation. There is an independent association of OSA with increased morbidity and mortality due to metabolic disorders, neurovascular and cardiovascular disease, and impaired neurocognitive func$\operatorname{tion}^{1-3}$. Snoring and daytime sleepiness are the main complaints and observed apnea is the most specific symptom. The epidemiological statistics show that $23.4 \%$ of females and $49.7 \%$ of males are diagnosed with OSA ${ }^{4}$.

Due to the growing number of patients suspected of having OSA being referred to sleep clinics, the screening methods have become increasingly important. The difficulty of diagnosis is related to the availability and accessibility of cardiorespiratory sleep studies. Consequently, a simple and reliable method for screening high-risk groups is needed.

The NoSAS Score test (Appendix A) is a simple and easily employed tool that assesses 5 parameters: Neck circumference, Obesity, Snoring, Age, and Sex and assigns 4 points for a neck circumference of more than $40 \mathrm{~cm}, 3$ points for a body-mass index of $25 \mathrm{~kg} /$ $\mathrm{m}^{2}$ to less than $30 \mathrm{~kg} / \mathrm{m}^{2}$, or 5 points for a body-mass index of $30 \mathrm{~kg} / \mathrm{m}^{2}$ or more, 2 points for snoring, 4 points for being older than 55 years, and 2 points for being male ${ }^{5}$. The score ranges from 0 to 17 and the patient has a high probability of OSA if they score 8 or higher in the NoSAS ${ }^{5}$. This allows the identification of individuals at risk for the disease and rules out others without risk, with a negative predictive value (NPV) of $90 \%$ and $98 \%$ in two different cohorts ${ }^{5}$. The NoSAS score has been validated in Portugal by standard validation instruments ${ }^{6}$.

The STOP-Bang questionnaire (Appendix B), is a scoring protocol containing eight Yes or No questions (score: $1 / 0$, ranging from a value of 0 to 8 ), making it a theoretically simple screening $\operatorname{method}^{7}$. A score of 3 or more revealed high sensitivity $(83.6 \%)$ for detecting OSA in a surgical population, but also for identifying moderate and severe OSA $(92.9 \%$ and $100 \%$, respectively) ${ }^{7}$. The STOP-Bang questionnaire has been validated in Portugal by standard translation and validation instruments ${ }^{8}$.

\section{METHODS}

Objective

The present study aimed to evaluate the performance of the NoSAS and STOP-Bang scores as screening tools for the diagnosis of OSA in a respiratory and sleep clinic.

\section{Study design}

A prospective study, 12 months in duration, beginning in January 2017. We consecutively enrolled all patients with a suspicious sleep disorder, referred by primary care physicians to our sleep unit for clinical evaluation, and who underwent in-lab polysomnography (PSG).

During the clinical consultation, every patient was asked if they accepted to participate in the study, regardless of the reasons for being referred, which included clinical suspicion of a specific sleep disorder or referral for isolated symptoms.

All patients included were required to complete the NoSAS and STOP-Bang questionnaires, with information concerning neck circumference, body mass index (BMI), snoring, age, gender, tiredness, observed apnea, and high blood pressure (blood pressure $>$ 140/90 mmHg or treatment for hypertension).

There was no interference by the research staff in the interpretation or completion of the questionnaires.

Patients previously diagnosed with OSA, additional diagnoses obtained throughout the sleep study (like obesity/hypoventilation syndrome, and central sleep apnea), all cases of technical error during data collection, and patients unable to read and/or write were excluded from the study.

\section{Sleep studies, scoring, and diagnosis}

At the specialized sleep center, all patients were submitted to a standard PSG, using the patient's usual bedtime, overnight. A standardized setting made up of surface electrodes was used and included: electroencephalogram, electrooculogram, electrocardiogram, and submental and lower limb EMG. Besides this data, additional information was collected regarding thoracic and abdominal respiratory effort, snoring and body position sensors, pulse oximetry, and oronasal airflow (thermistor and pressure sensor). A certified PSG technician scored the PSG recordings under the supervision of a sleep physician who reviewed the final reports. The sleep physician and technician were both blinded to the study report (clinical information, NoSAS, and 
STOP-Bang questionnaires). The scoring was made manually, following the recommendations of the American Academy of Sleep Medicine ${ }^{9}$. Apnea was defined as a decrease of at least $90 \%$ of airflow from baseline, lasting 10 seconds or longer. Hypopneas was defined as a decrease of at least $30 \%$ of airflow from baseline, lasting 10 seconds, associated with either arousal or $\mathrm{a} \geq 3 \% \mathrm{O} 2$ saturation decrease. The mean number of apneas and hypopneas per hours of sleep (apnea-hypopnea index [AHI]) was calculated. Both diagnosis and severity of OSA were classified based on the AHI: $>5-15 / \mathrm{h}$ - mild, $>15-30 / \mathrm{h}$ - moderate, and $>30 / \mathrm{h}-$ severe $^{9,10}$.

Additional diagnoses obtained throughout the sleep study were defined according to the International Classification of Sleep Disorders - Third Edition $^{11}$. However, our study was exclusively focused on OSA, so all other diagnoses were ignored or excluded.

\section{Statistical Analysis}

Statistical analysis was carried out using the IBM SPSS ${ }^{\circledR}$ statistical program, version 25 (the Statistical Package for the Social Sciences).

The categorical variables were described with frequencies and percentages and the quantitative variables with mean, median, standard deviation, maximum, and minimum. All associations between the presence of OSA and each of the possible risk factors were established using logistic regression, which estimated their odds ratios (ORs). The Wald test was considered significant when its p-value did not exceed 0.05.

To measure the diagnostic ability of the NoSAS and STOP-Bang scores for different AHI cut-offs, we determined the area under the receiver operating characteristic (ROC) curve and the value of the score where both sensitivity and specificity maximized.

\section{RESULTS}

Of the 294 patients, $70.7 \%$ were male, aged 53.5 \pm 12.1 years, with a neck circumference of $41.0 \pm 3.6$ $\mathrm{cm}$ and a BMI of $30.8 \pm 5.1 \mathrm{~kg} / \mathrm{m} 2$. OSA was present in $84.0 \%$ of the patients, $28.8 \%$ with mild OSA, $34.8 \%$ moderate, and $36.4 \%$ severe. Descriptive summary statistics and comparison of OSA and non-OSA groups are displayed in Table 1.

Using the NoSAS score for predicting OSA, moderate to severe OSA, and severe OSA, the area under the ROC curve (AUC) was: 0.770 (95\% CI: 0.703-0.837), $\mathrm{p}<0.001$, sensitivity of $57.5 \%$ and specificity of $83.0 \%$ for a score of 12 ; 0.746 (95\% CI: 0.691-0.802), $p<0.001$, sensitivity of $68.2 \%$ and specificity of $75.4 \%$ for a score of 13 ; 0.686 (95\% CI: 0.6220.749 ), $p<0.001$, sensitivity of $71.1 \%$ and specificity of $58.3 \%$ for a score of 13 , respectively. Using the STOP-Bang score for predicting OSA, moderate to severe OSA, and severe OSA, the AUC was: 0.862 (95\% CI: 0.808-0.916), $\mathrm{p}<0.001$, sensitivity of $68.4 \%$ and specificity of $85.1 \%$ for a score of 5 ; 0.813 (95\% CI: 0.756-0.861), $\mathrm{p}<0.001$, sensitivity of $77.3 \%$ and specificity of $66.1 \%$ for a score of 5 ; 0.787 (95\% CI: $0.732-0.841), p<0.001$, sensitivity of $70.0 \%$ and specificity of $79.9 \%$ for a score of 6 , respectively. Figure 1 illustrates these results.

The predicted probabilities of having OSA of a specific severity with the corresponding NoSAS score are illustrated in Figure 2. With each incremental increase in the score, from 0 to 7 , the probability of having no sleep apnea diminished, while the probability of having mild, moderate, or severe sleep apnea increased continuously. With any score greater than 7 , only the probability of having moderate or severe sleep apnea increased. With a score greater than 13 , only the probability of having severe sleep apnea increased.

The predicted probabilities of having OSA of a specific severity with the corresponding STOP-Bang score are also illustrated in Figure 2. With each incremental increase in the score from 0 to 3 , the probability of having no sleep apnea diminished, while the probability of having mild, moderate, or severe sleep apnea increased continuously. With any score greater than 4, only the probability of having moderate or severe sleep apnea increased. With a score greater than 5 , only the probability of having severe sleep apnea increased.

\section{DISCUSSION}

Due to the high prevalence of undiagnosed OSA and its comorbidities, a quick and reliable screening tool is needed for a prompt prediction of OSA. Since they can be applied and scored easily, as part of routine daily practice, questionnaires can be appropriate tools for that purpose. Moreover, analysis of the questionnaire performance in specific populations can provide clinicians with a set of predictive parameters for different levels of OSA severity, which can 
be used as a crucial guide for diagnostic and therapeutic decisions.

In our study, the present results show that both scores can add great value and be a very useful and powerful tool in primary care. Overall, the diagnostic ability of the STOP-Bang was higher than the NoSAS. This could be explained by the fact that the STOPBang (and not NoSAS) assesses important parameters, including excessive daytime sleepiness, observed apnea, and high blood pressure. Moreover, excessive daytime sleepiness evaluated by the Epworth's Score was more prevalent in the OSA group, reflecting that the Epworth Score must be used as a complement.

Numerous questionnaires and other clinical screening tools for OSA have been analyzed previously and some papers are worth being mentioned. A study by Tan et al. ${ }^{12}$ evaluated STOP-Bang and compared its performance to the NoSAS score and Berlin questionnaires. They concluded that the performance of all three questionnaires were similar to the AUC values clustered around $0.682-0.748^{12}$. In regard to the validation of a Portuguese version of the STOP-Bang in primary care, by Rebelo-Marques et al. ${ }^{8}$, when using this model for the prediction of OSA, the diagnostic ability of the STOP-Bang was superior to the NoSAS score (the AUC was 0.847). According to Lye et al. ${ }^{13}$, the AUC of the NoSAS score (0.724) was higher than that of the Epworth Sleepiness Scale (ESS) (0.544). They concluded that overall the NoSAS score performed better than the ESS $^{13}$. A systematic review of screening questionnaires for OSA by Abrishami et al. ${ }^{14}$

\section{APPENDIX A}

\section{NoSAS score}

1: Neck circumference $>40 \mathrm{~cm}-4$ points

2: Obesity

- BMI $25 \mathrm{~kg} / \mathrm{m}^{2}$ to $<30 \mathrm{~kg} / \mathrm{m}^{2}-3$ points

- BMI $\geq 30 \mathrm{~kg} / \mathrm{m}^{2}$ - 5 points

3: Snoring - 2 points

4: Age $>55$ years -4 points

5: Sex: male -2 points concluded that the evidence regarding the accuracy of OSA questionnaires is associated with promising but inconsistent results. This inconsistency could be due to studies with heterogeneous designs (population, questionnaire type, and validity). Nevertheless, the STOP-Bang questionnaire is suggested due to its higher methodological quality, accurate results, and easy to use features ${ }^{14}$.

Furthermore, our study has limitations that must be mentioned. The fact that our sample consisted mainly of obese men with an average age of over 50 years may have conditioned our results.

\section{CONCLUSIONS}

The ROC area was consistently high for both scores, confirming the diagnostic ability of the NoSAS and STOP-Bang questionnaires for all OSA severities. Thus, our results suggest that these questionnaires may be a powerful tool for the screening and stratification of patients in the diagnosis of OSA and can help primary care clinicians decide which patients to further investigate with a nocturnal recording. The Epworth Score must be used as a complement. Overall, the diagnostic ability of the STOP-Bang was higher than the NoSAS. Nevertheless, more studies are needed to evaluate the efficacy of these scores in younger populations, with a predominance of female and non-obese individuals, in cardiovascular disease or minimally symptomatic patients.

\section{APPENDIX B}

STOP-Bang questionnaire

1: Do you SNORE loudly (louder than talking or loud enough to be heard through closed doors)?

2: Do you often feel TIRED, fatigued, or sleepy during daytime?

3: Has anyone OBSERVED you stop breathing during your sleep?

4: Do you have or are you being treated for high blood PRESSURE?

5: BMI more than $35 \mathrm{~kg} / \mathrm{m} 2$ ?

6: AGE over 50 years old?

7: NECK circumference $>16$ inches $(40 \mathrm{~cm})$ ?

8: GENDER: Male? 


\section{ANNEXES}

FIGURE 1. AREA UNDER THE ROC CURVE (AUC) FOR ALL OSA (AHI: >5/H), MODERATE TO SEVERE OSA (AHI: >15/H) AND SEVERE OSA (AHI: >30/H)
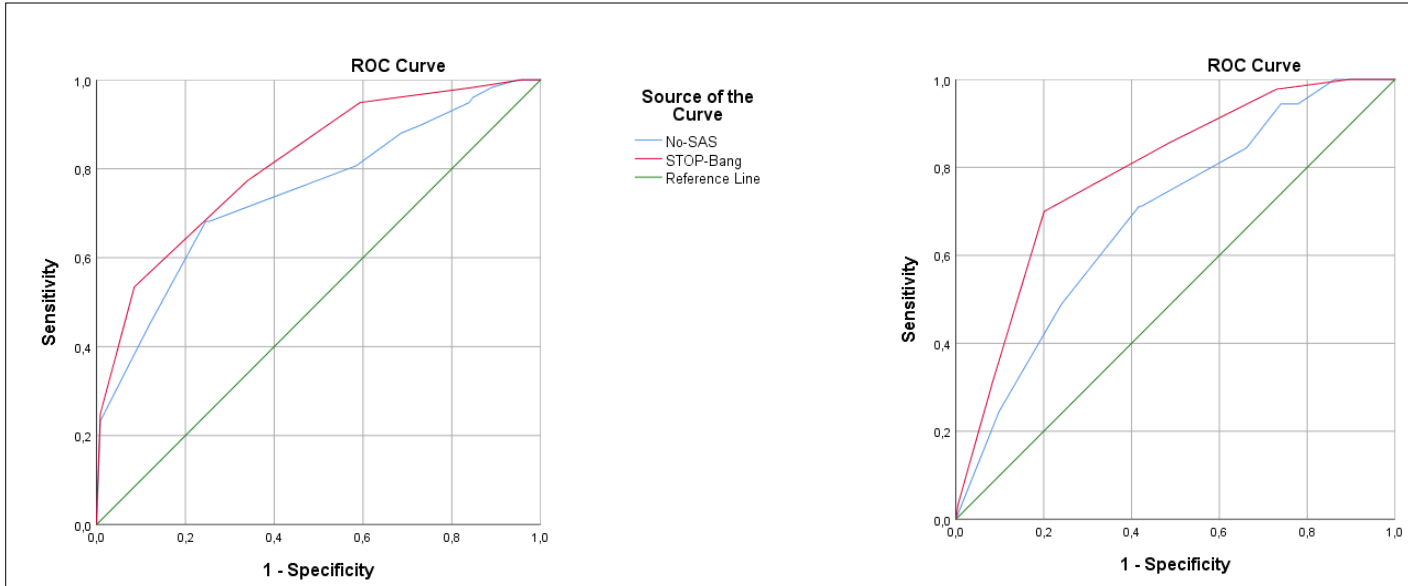

Source of the
Curve

Source of th
Curve

- No-SAS

- Reference Lin

- No-SAS
- STOP-Bang
- Reference Line

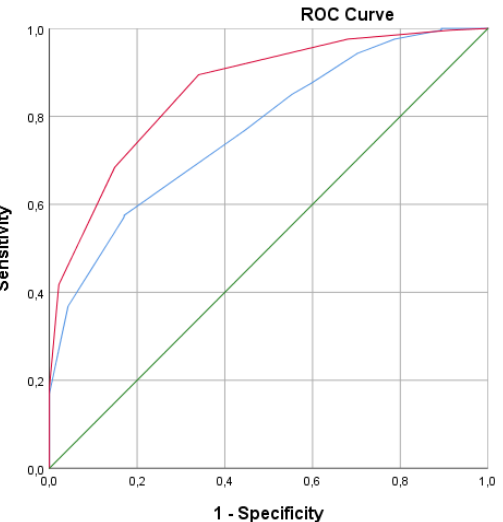

Source of the
Curve

- No-SAS

— STOP-Bang

FIGURE 2. PLOT OF PREDICTED PROBABILITIES FOR DIFFERENT OSA SEVERITIES WITH THE CORRESPONDING NOSAS AND STOP-BANG SCORES.

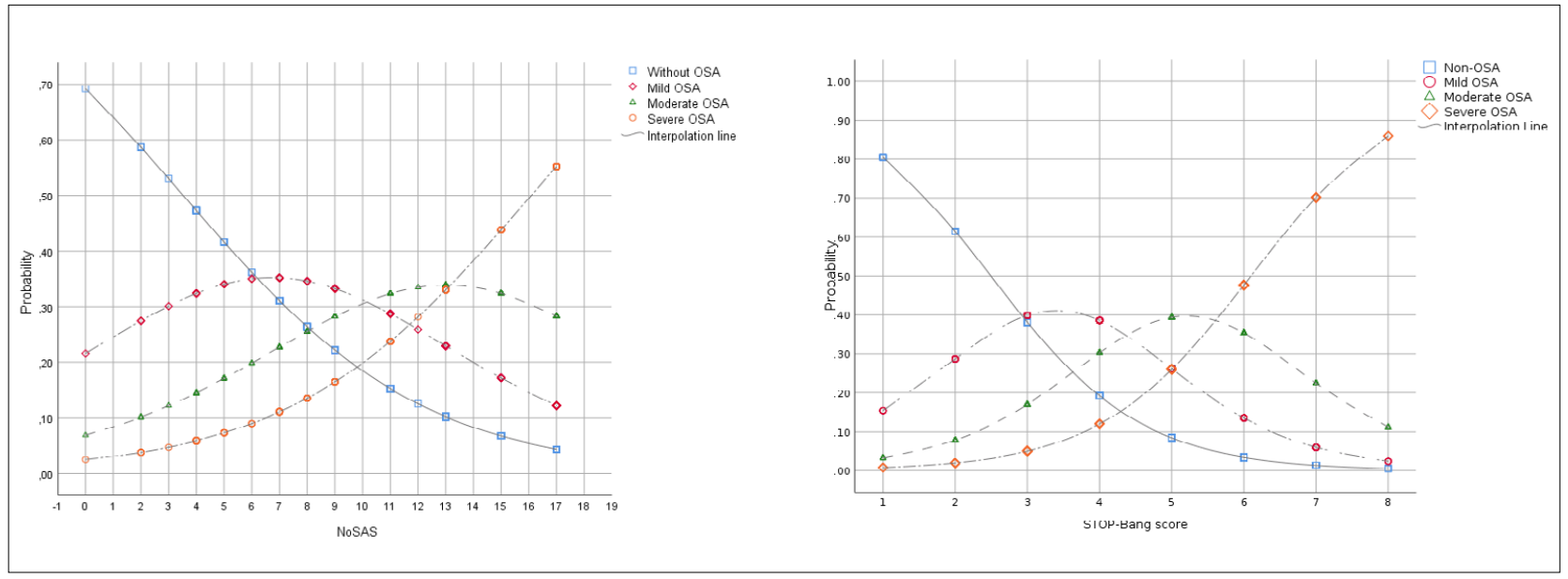


TABLE 1. SUMMARY STATISTICS OF THE PATIENT POPULATION AND COMPARISON OF THE OSA AND NON-OSA GROUPS.

\begin{tabular}{|c|c|c|c|c|}
\hline \multirow[t]{2}{*}{ Variable } & \multicolumn{2}{|l|}{ OSA } & \multirow{2}{*}{$\begin{array}{l}\text { OR - Yes/No } \\
\text { (Cl 95\%); } \\
\text { Logistic Regression }\end{array}$} & \multirow[t]{2}{*}{$\mathrm{Pa}$} \\
\hline & $\begin{array}{l}\text { Yes } \\
N=247(84.0 \%)\end{array}$ & $\begin{array}{l}\text { No } \\
\mathrm{N}=47(16.0 \%)\end{array}$ & & \\
\hline $\begin{array}{l}\text { Age (years) } \\
\text { Average } \pm \text { SD } \\
\text { Median(mín; máx) }\end{array}$ & $\begin{array}{l}55.81 \pm 11.43 \\
56(20 ; 82)\end{array}$ & $\begin{array}{l}47.49 \pm 13.06 \\
47(23 ; 77)\end{array}$ & 1.062 (1.032; 1.093) & $<0.001$ \\
\hline $\begin{array}{l}\text { Tiredness }(n)(\%) \\
\text { Yes } \\
\text { No }\end{array}$ & $\begin{array}{l}150(60.7) \\
97(39.3)\end{array}$ & $\begin{array}{l}22(46.8) \\
25(53.2)\end{array}$ & $\begin{array}{l}1.757(0.938 ; 3.291) \\
1\end{array}$ & 0.078 (NS) \\
\hline $\begin{array}{l}\text { Observed apnea }(n)(\%) \\
\text { Yes } \\
\text { No }\end{array}$ & $\begin{array}{l}179(72.5) \\
68(27.5)\end{array}$ & $\begin{array}{l}16(34.0) \\
31(66.0)\end{array}$ & $\begin{array}{l}5.100(2.623 ; 9.915) \\
1\end{array}$ & $<0.001$ \\
\hline $\begin{array}{l}\text { Pessure (high blood) } \\
\text { Yes } \\
\text { No }\end{array}$ & $\begin{array}{l}150(60.7) \\
97(39.3)\end{array}$ & $\begin{array}{l}14(29.8) \\
33(70.2)\end{array}$ & $\begin{array}{l}3.645(1.855 ; 7.161) \\
1\end{array}$ & $<0.001$ \\
\hline $\begin{array}{l}\text { Epworth's Score } \\
\text { Average } \pm \text { SD } \\
\text { Median(min; max) }\end{array}$ & $\begin{array}{l}10.97 \pm 5.35 \\
11(1 ; 24)\end{array}$ & $\begin{array}{l}9.15 \pm 5.19 \\
8(2 ; 20)\end{array}$ & $1.067(1.004 ; 1.135)$ & 0.036 \\
\hline $\begin{array}{l}\text { Minimum saturation } \\
\text { Average } \pm \mathrm{SD} \\
\text { Median (min; max) }\end{array}$ & $\begin{array}{l}78.41 \pm 10.63 \\
81.0(0.0 ; 92.0)\end{array}$ & $\begin{array}{l}88.30 \pm 4.34 \\
90.0(74.0 ; 95.7)\end{array}$ & $0.731(0.657 ; 0.814)$ & $<0.001$ \\
\hline $\begin{array}{l}\text { Neck circ. }>40 \mathrm{~cm}(\mathrm{n})(\%) \\
\text { Yes } \\
\text { No }\end{array}$ & $\begin{array}{l}150(60.7) \\
97(39.3)\end{array}$ & $\begin{array}{l}9(19.1) \\
38(80.9)\end{array}$ & $\begin{array}{l}6.529(3.023 ; 14.104) \\
1\end{array}$ & $<0.001$ \\
\hline $\begin{array}{l}\text { Obesity }(n)(\%) \\
\text { BMI<25 } \\
\text { BMI } 25-30 \\
\text { BMI } \geq 30\end{array}$ & $\begin{array}{l}14(5.7) \\
102(41.3) \\
131(53.0) \\
\end{array}$ & $\begin{array}{l}13(27.7) \\
21(44.6) \\
13(27.7) \\
\end{array}$ & $\begin{array}{l}1 \\
4.510(1.854 ; 10.973) \\
9.357(3.634 ; 24.096)\end{array}$ & $\begin{array}{l}<0.001 \\
0.001 \\
<0.001\end{array}$ \\
\hline $\begin{array}{l}\text { Snoring }(n)(\%) \\
\text { Yes } \\
\text { No }\end{array}$ & $\begin{array}{l}241(97.6) \\
6(2.4)\end{array}$ & $\begin{array}{l}42(89.4) \\
5(10.6)\end{array}$ & $\begin{array}{l}4.782(1.396 ; 16.380) \\
1\end{array}$ & 0.013 \\
\hline $\begin{array}{l}\text { Gender }(n)(\%) \\
\text { Female } \\
\text { Male }\end{array}$ & $\begin{array}{l}63(25.5) \\
184(74.5)\end{array}$ & $\begin{array}{l}23(48.9) \\
24(51.1)\end{array}$ & $\begin{array}{l}1 \\
2.799(1.477 ; 5.305)\end{array}$ & 0.002 \\
\hline
\end{tabular}

a Teste de Wald; Abbreviations: OR = odds ratio; $\mathrm{Cl}$ = Confidence Interval; BMI: body mass index; OSA: obstructive sleep apnea; NS: not significant.

\section{RESUMO}

INTRODUÇÃO: Na atualidade tem se verificado um crescimento significativo no número de doentes com suspeita de apneia obstrutiva do sono (AOS) referenciados para consulta do sono. Nesse sentido, instrumentos de rastreio e estratificação da gravidade dessa patologia têm se tornado cada vez mais relevantes.

OBJETIVO: Avaliar e comparar o desempenho da escala NoSAS e Stop-Bang para o rastreio de AOS.

MÉTODOS: Estudo prospectivo durante 12 meses. Avaliados todos os doentes encaminhados aos cuidados de saúde primários do centro de medicina do sono que completaram o questionário NoSAS (Neck circumference, Obesity, Snoring, Age, Sex), Stop-Bang (Snoring, Tiredness, Observed apnea, Pressure [high blood], BMI, Age, Neck circumference, Gender) e foram submetidos a polissonografia. Utilizou-se uma análise ROC (receiver operating characteristic) para encontrar as pontuações que maximizam simultaneamente a sensibilidade e especificidade para cada diagnóstico.

RESULTADOS: Incluídos 294 indivíduos, 84\% apresentavam AOS, sendo que em 28,8\% a OAS era ligeira, 34,8\% moderada e 36,4\% grave.

USANDO A ESCALA NOSAS PARA PREVISÃO DE AOS, AOS MODERADA A GRAVE E AOS GRAVE, A ÁREA ROC FOI: 0,770 (IC95\%: 0,703-0,837), p<0,001, sensibilidade de 57,5\% e especificidade de 83,0\% para a pontuação 12); 0,746 (IC95\%: 0,691- 0,802), p<0,001, sensibilidade de 68,2\% e especificidade de 75,4\% para a pontuação 13); 0,686 (IC95\%: 0,622-0,749), p<0,001, sensibilidade de 71,1\% e especificidade de $58,3 \%$ para a pontuação 13$)$, respectivamente.

USANDO A ESCALA STOP-BANG PARA A PREVISÃO DE AOS, AOS MODERADA A GRAVE E AOS GRAVE, A ÁREA ROC FOI: 0,862 (IC95\%: 0,808-0,916), p<0,001, sensibilidade de 68,4\% e especificidade de 85,1\% para pontuação 5); 0,813 (IC95\%: 0,756-0,861), p<0,001, sensibilidade de $77,3 \%$ e especificidade de 66,1\% para a pontuação 5); 0,787 (IC95\%: 0,732-0,841), p<0,001, sensibilidade de 70,0\% e especificidade de 79,9\% para a pontuação 6), respectivamente. 
CONCLUSÕES: A área ROC foi consistentemente alta para as duas escalas, confirmando a capacidade diagnóstica dos questionários NoSAS e Stop-Bang para todos os graus de gravidade de AOS. Assim, os nossos resultados sugerem que esses questionários podem ser um importante instrumento para rastreio e estratificação de doentes no diagnóstico de AOS. Globalmente, a capacidade de diagnóstico do Stop-Bang foi superior à do NoSAS.

PALAVRAS-CHAVE: Apneia obstrutiva do sono. Inquéritos e questionários. Inquéritos epidemiológicos.

\section{REFERENCES}

1. Young T, Finn L, Peppard E, Szklo-Coxe M, Austin D, Nieto Fl, et al. Sleep disordered breathing and mortality: eighteen-year follow-up of the Wisconsin sleep cohort. Sleep. 2008;31(8):1071-8.

2. Marshall NS, Wong KK, Liu PY, Cullen SR, Knuiman MW, Grunstein RR. Sleep apnea as an independent risk factor for all-cause mortality: the Busselton Health Study. Sleep. 2008;31(8):1079-85.

3. McNicholas WT, Bonsignore MR; Management Committee of EU COST ACTION B26. Sleep apnoea as an independent risk factor for cardiovascular disease: current evidence, basic mechanisms and research priorities. Eur Respir J. 2007;29(1):156-78.

4. Heinzer R, Vat S, Marques Vidal P, Marti-Soler H, Andries D, Tobback N, et al. Prevalence of sleep-disordered breathing in the general population: the HypnoLaus study. Lancet Respir Med. 2015;3(4):310-8.

5. Marti-Soler H, Hirotsu C, Marques-Vidal P, Vollenweider P, Waeber G, Preisig M, et al. The NoSAS score for screening of sleep-disordered breathing: a derivation and validation study. Lancet Respir Med. 2016;4(9):742-8.

6. Coutinho Costa |, Rebelo-Marques A, Machado IN, Gama |MR, Santos C, Teixeira F, et al. Validation of NoSAS (Neck, Obesity, Snoring, Age, Sex) score as a screening tool for obstructive sleep apnea: analysis in a sleep clinic. Pulmonology. 2019;25(5):263-70.

7. Chung F, Yegneswaran B, Liao P, Chung SA, Vairavanathan S, Islam S, et al. STOP questionnaire: a tool to screen patients for obstructive sleep apnea. Anesthesiology. 2008;108(5):812-21.
8. Rebelo-Marques A, Vicente C, Valentim B, Agostinho M, Pereira R, Teixeira $M F$, et al. STOP-Bang questionnaire: the validation of a Portuguese version as a screening tool for obstructive sleep apnea (OSA) in primary care. Sleep Breath. 2018;22(3):757-65.

9. Berry RB, Brooks R, Gamaldo C, Harding SM, Lloyd RM, Quan SF, et al. AASM scoring manual updates for 2017 (Version 2.4). J Clin Sleep Med. 2017;13(5):665-6

10. Epstein LJ, Kristo D, Strollo Jr PJ, Friedman N, Malhotra A, Patil SP, et al; Adult Obstructive Sleep Apnea Task Force of the American Academy of Sleep Medicine. Clinical guideline for the evaluation, management and long-term care of obstructive sleep apnea in adults. J Clin Sleep Med. 2009;5(3):263-76.

11. Sateia MJ. International classification of sleep disorders - third edition: highlights and modifications. Chest. 2014;146(5):1387-94.

12. Tan A, Hong Y, Tan LWL, van Dam RM, Cheung YY, Lee $C H$. Validation of NoSAS score for screening of sleep-disordered breathing in a multiethnic Asian population. Sleep Breath. 2017;21(4):1033-8.

13. Lye PSP, Soh RY, Chua AP, Tan A. Using NoSAS score to predict severe obstructive sleep apnea in a clinic-based population. Respirology. 2018;23(Suppl. 2):195

14. Abrishami A, Khajehdehi A, Chung F. A systematic review of screening questionnaires for obstructive sleep apnea. Can J Anaesth. 2010;57(5):423-38. 